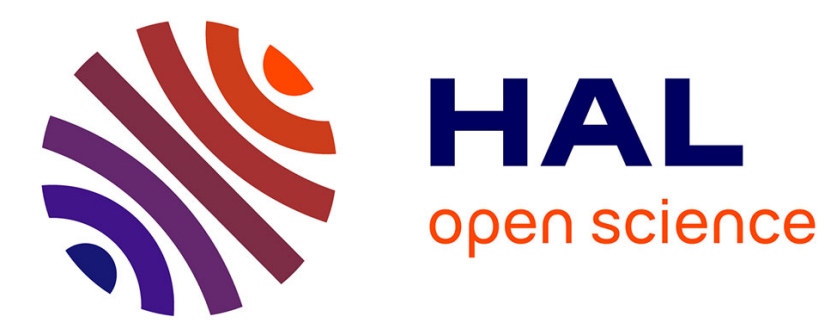

\title{
Isothermal Crystallization Kinetics of In Situ Photo and Thermo Aged Poly(Ethylene Oxide) Using PhotoDSC
}

Frédéric Fraisse, Jean-Marie Nedelec, Jean-Pierre E. Grolier, Mohamed Baba

\section{To cite this version:}

Frédéric Fraisse, Jean-Marie Nedelec, Jean-Pierre E. Grolier, Mohamed Baba. Isothermal Crystallization Kinetics of In Situ Photo and Thermo Aged Poly(Ethylene Oxide) Using PhotoDSC. Physical Chemistry Chemical Physics, 2007, 9, pp.2137-2141. 10.1039/b618701c . hal-00154672

\section{HAL Id: hal-00154672 \\ https://hal.science/hal-00154672}

Submitted on 14 Jun 2007

HAL is a multi-disciplinary open access archive for the deposit and dissemination of scientific research documents, whether they are published or not. The documents may come from teaching and research institutions in France or abroad, or from public or private research centers.
L'archive ouverte pluridisciplinaire $\mathbf{H A L}$, est destinée au dépôt et à la diffusion de documents scientifiques de niveau recherche, publiés ou non, émanant des établissements d'enseignement et de recherche français ou étrangers, des laboratoires publics ou privés. 


\title{
Isothermal Crystallization Kinetics of In Situ Photo and Thermo Aged Poly(Ethylene Oxide) Using PhotoDSC
}

Frédéric FRAÏSSE ${ }^{1}$, Jean-Marie NEDELEC ${ }^{2}$, Jean Pierre E. GROLIER ${ }^{3}$ and Mohamed BABA ${ }^{1,3^{*}}$

${ }^{1}$ Laboratoire de Photochimie Moléculaire et Macromoléculaire UMR-CNRS 6505

${ }^{2}$ Laboratoire des Matériaux Inorganiques, UMR CNRS 6002

${ }^{3}$ Laboratoire de Thermodynamique des Solutions et des Polymères, UMR CNRS 6003

TransChiMiC

Université Blaise Pascal et Ecole Nationale Supérieure de Chimie de Clermont-Ferrand 24 avenue des Landais 63177 Aubière France.

\begin{abstract}
Isothermal crystallization of a high molecular weight PEO $\left(\mathrm{M}_{\mathrm{w}}=4,000,000\right)$ has been investigated using photoDSC. Combining light irradiation, heating and DSC analysis, photoDSC demonstrates a good capability to follow the in situ photo and thermo ageing of semi-crystalline polymers. Isothermal crystallization of PEO has been performed at $55^{\circ} \mathrm{C}$. After ageing at different temperatures ranging from 0 to $90^{\circ} \mathrm{C}$ and for various periods of time, the kinetics of this crystallization has been found following Avrami theory. Avrami exponent, $\mathrm{n}$, was found between 0.9 and 1.4 evidencing a one-dimension growth process. It was also found that the isothermal crystallization rate (i.e. reciprocal crystallization half-time) was exposure time, ageing temperature and light intensity dependent which makes this kinetic parameter a good indicator to follow and to compare the degradation of the semi-crystalline polymers.
\end{abstract}

\section{Key Words}

PhotoDSC, PEO, isothermal crystallization, Avrami, in situ ageing, polymers.

\footnotetext{
* Corresponding author: e-mail mohamed.baba@univ-bpclermont.fr

Phone $0033(0) 473407161$

Fax $0033(0) 473407095$
} 


\section{Introduction}

The crystallization processes of semi-crystalline polymers are very sensitive to the thermal and mechanical "history" of the material. Ability of the polymer to crystallize (also called "crystallizability") is strongly dependent on the capability of its macromolecular chains to move and to adopt the right conformation. Photo-oxydation in out door or in accelerated condition as well as thermo-oxydation lead to large modification in the polymeric architecture. In this paper, the crystallizability was used as a degradation progress indicator. PhotoDSC, combining in a single device irradiation, heating and DSC analysis, was considered for measuring the rate of isothermal crystallization of poly (ethylene oxide) (PEO) irradiated and heated at various temperatures. Isothermal crystallization of semi-crystalline polymers has been widely studied [1-4]. Avrami analysis is the most popular and easiest methodology to reach relevant parameters to characterize the crystallization kinetics of these materials. A well-documented paper, comparing Avrami, Tobin, Malkin and UrbanoviciSegal macrokinetic models has been published by Supaphol [5]. According to Supaphol's work, Avrami model is still one of the best with Urbanovici-Segal one, we consequently considered Avrami theory since it is easy and reliable enough to reach our specific goal.

PEO is a semi-crystalline water-soluble polymer [6,7], with a crystallinity which is very sensitive to the thermal history of the samples, making this property interesting as an indicator of degradation. Because it is a biodegradable and biocompatible polymer, PEO is a good candidate for environmental and medical applications $[8,9,10]$. The mechanisms of thermo and photooxidation of PEO have already been investigated [11, 12] on the basis of IR identifications of the oxidation products.

\section{Experimental section}

Materials

Poly(ethylene oxide) with high molecular weight $\left(\mathrm{M}_{\mathrm{w}}=4,000,000\right)$ was used. It was supplied by Scientific Polymer Products and used without further purification. The polymer is under white powder form. PEO is a semi-crystalline polymer. It exhibits a melting endotherm centred around $57^{\circ} \mathrm{C} \quad\left(\mathrm{T}_{\mathrm{m}}\right)$ and a crystallization peak showing a large supercooling phenomenon starting at $35^{\circ} \mathrm{C}$.

\section{Methods}


The photoDSC device used in this study was already described in $(13,14)$. It combines light irradiation and DSC analysis applied to a single sample using a Hamamatsu light generator equipped with a Lightningcure200 source (Xe/Hg, "medium pressure") and a Metter Toledo DSC $822^{\mathrm{e}}$ apparatus. The DSC device was equipped with an Intracooler unit providing a cooling rate up to $50{ }^{\circ} \mathrm{C} \cdot \mathrm{min}^{-1}$. Temperature and energy calibration was performed using an indium standard sample $\left(\mathrm{T}_{\mathrm{m}}=156.6^{\circ} \mathrm{C}\right.$ and $\left.\Delta \mathrm{H}=28.5 \mathrm{~J}^{-\mathrm{g}^{-1}}\right)$. Aluminium DSC crucibles with $40 \mu \mathrm{L}$ in capacity were used. No cover was used in order to bring the light beam directly onto the sample. All DSC runs were carried out under air atmosphere flow with $20 \mathrm{~mL} \mathrm{~min}^{-1}$ as flow rate.

Figure 1 should around be here

Figure 1 shows the details of the experimental measurements. In order to evaluate the specific contribution of heating and irradiation during the ageing of polymer, two series of runs have been performed. The first one was carried out with a simple heating in darkness whereas the second run was carried out under irradiation. For photo-ageing experiments (Figure $1 \mathrm{a}$ ), the sample was heated to the chosen ageing temperature $\left(T_{a} \leq 60^{\circ} \mathrm{C}\right.$, for instance $T_{a}=35^{\circ} \mathrm{C}$ in Figure 1a) for two minutes in darkness followed by a selected irradiation time increment $\left(t_{i}\right)$. After $t_{i}$ irradiation time, light was turned off and the sample heated at $10^{\circ} \mathrm{C} \cdot \mathrm{min}^{-1}$ up to $80^{\circ} \mathrm{C}$. After 2 minutes at $80^{\circ} \mathrm{C}$, the melting was completed and a fast cooling $\left(20^{\circ} \mathrm{C} \cdot \mathrm{min}^{-1}\right)$ was imposed to the chosen isothermal crystallization temperature $\left(T_{c}=55^{\circ} \mathrm{C}\right)$. Sample was then maintained at this temperature for 90 minutes in order to assure complete isothermal crystallization. Immediately after isothermal crystallization, the sample temperature was changed to $T_{a}$ and a new cycle was initiated. In order to check whether or not premature crystallization occurs during the fast cooling, a separate experiment was performed. In this experiment, instead of waiting at $T_{c}$ for sample to completely crystallize, a heating scan was immediately performed as soon the thermal stabilisation was reached. No melting peak was observed in this subsequent heating scan. This observation was also supported by the absence of crystallization peak during the cooling segment. Four photo-ageing temperatures were investigated: $0,15,35$ and $60^{\circ} \mathrm{C}$. For $\mathrm{T}_{\mathrm{a}}>60^{\circ} \mathrm{C}$, changes induced by photo ageing were too fast and no isothermal crystallization peak was observed even after very short time increment. For thermal oxidation experiments, the temperature program is shown in figure $1 \mathrm{~b}\left(\mathrm{~T}_{\mathrm{a}}=80^{\circ} \mathrm{C}\right)$. Except for the lighting step, the same experimental procedure was followed. Four ageing 
temperatures were selected: $60,75,80$ and $90^{\circ} \mathrm{C}$. The crystallization after thermal ageing at temperatures lower than $60^{\circ} \mathrm{C}$ was found too slow to be carried out in a reasonable experimental time.

\section{Results}

Figures 2a and 3a show typical series of DSC exotherms of isothermal crystallization of PEO photo and thermo-aged at 15 and $80^{\circ} \mathrm{C}$ respectively for various exposure times. The isothermal crystallization temperature was $55^{\circ} \mathrm{C}$ in each case. Upon increasing irradiation or cure time, the isothermal crystallization peaks become wider and their top temperature shifts towards the longer times. In figures $2 b$ and $3 b$ are represented the integral curves from the DSC exotherms of isothermal crystallization whereas in Figures $2 \mathrm{c}$ and $3 \mathrm{c}$ are plotted two representations of the relative crystallinity, $\alpha(t)$, as a function of crystallization time, $t$. The relative crystallinity can be defined as follows:

$$
\alpha(t)=\frac{\Delta H(t)}{\Delta H_{\infty}}
$$

$\Delta H(t)$ is the enthalpy of isothermal crystallization at $t$ and $\Delta H_{\infty}$ its value after complete crystallization.

A relevant kinetic characterisation, obtained by derivation from the relative crystallinity plots, is the crystallization half time $\left(t_{0.5}\right)$. This time corresponds to the time necessary for the polymer to reach $50 \%$ of its maximum crystallinity. The reciprocal value of $t_{0.5}$ is assumed to be equal to the experimental rate $\left(G_{\text {exp }}\right)$ of the isothermal crystallization. Tables 1 and 2 summarize the $G_{\exp }$ values as derived from Figures $2 \mathrm{c}$ and $3 \mathrm{c}$. It can be noted that the crystallization rate decreases continuously when the irradiation or the curing time increases.

Figure 2 should around be here

Figure 3 should be around here

\begin{tabular}{cccccccc}
\hline $\mathrm{t} / \mathrm{s}$ & 0 & 30 & 60 & 90 & 120 & 150 & 180 \\
\hline $\mathrm{t}_{0.5 \exp } / \mathrm{s}$ & 105.3 & 137.3 & 159.8 & 179.8 & 207.8 & 262.3 & 345.6 \\
$\mathrm{G}_{\exp } \times 10^{3} / \mathrm{s}^{-1}$ & 9.5 & 7.3 & 6.3 & 5.6 & 4.8 & 3.8 & 2.9 \\
\hline
\end{tabular}


Table 1: Crystallization half-times $\left(\mathrm{t}_{0.5 \exp }\right)$ and experimental crystallization rate $\left(\mathrm{G}_{\text {exp }}\right)$ for photo-oxidation of PEO at $15^{\circ} \mathrm{C}$. Tc was $55^{\circ} \mathrm{C}$.

\begin{tabular}{cccccccccccc}
\hline $\mathrm{t} / \mathrm{s}$ & 0 & 120 & 240 & 360 & 480 & 600 & 720 & 840 & 960 & 1080 & 1200 \\
\hline $\mathrm{t}_{0.5 \exp } / \mathrm{s}$ & 101.3 & 163.5 & 196.4 & 211.3 & 223.1 & 234.2 & 242.8 & 249.5 & 254.9 & 260.7 & 266.2 \\
$\mathrm{G}_{\exp } \times 10^{3} / \mathrm{s}^{-1}$ & 9.9 & 6.1 & 5.1 & 4.7 & 4.5 & 4.2 & 4.1 & 4.0 & 3.9 & 3.8 & 3.7 \\
\hline
\end{tabular}

Table 2: Crystallization half-times $\left(\mathrm{t}_{0.5 \exp }\right)$ and experimental crystallization rate $\left(\mathrm{G}_{\text {exp }}\right)$ for thermo-oxidation at $75^{\circ} \mathrm{C}$.

More kinetic information can be obtained from these experimental data by application of Avrami formalism (15-17). Fundamental Avrami equation can be expressed as:

$$
\alpha(t)=1-\exp \left(-k_{a} t^{n}\right) \quad(\text { Eq. } 2)
$$

where $k_{a}$ is Avrami rate constant and $n$ Avrami exponent.

The value of Avrami exponent is assumed ranging from 1 to 4 and is related to the geometric characteristics of nuclei: $n=1$ being ascribed to a rod, 2 to pellets and 3 or 4 to threedimensional structure.

To calculate $k_{a}$ and $n$, a log-log graphic representation is classically used:

$$
\log (-\ln (1-\alpha(t)))=\log \left(k_{a}\right)+n \log (t) \quad \text { (Eq. 3) }
$$

Thus, if the experimental data obey to Avrami theory, the plot of $\log (-\ln (1-\alpha(t)))$ as a function of $\log (\mathrm{t})$ should be linear yielding $\log \left(k_{a}\right)$ as intercept and $n$ as slop.

Figure $2 \mathrm{~d}$ and $3 \mathrm{~d}$ show Avrami plots related to photo- and thermo-aged PEO at 15 and $80^{\circ} \mathrm{C}$ respectively. These plots were drawn for $\alpha(\mathrm{t})$ ranging between 0.1 and 0.56 . To investigate whether or not the crystallization of PEO follows Avrami model's, the half-time crystallization values were calculated from the knowledge of $k_{a}$ and $n$.

In fact, it can be written: 


$$
G_{c a l}=\frac{1}{t_{0.5 c a l}}=\frac{1}{\left(\frac{\ln 2}{k_{a}}\right)^{\frac{1}{n}}}
$$

where $t_{0.5 c a l}$ is the calculated half-time crystallization and $G_{c a l}$ the calculated crystallization rate.

In Tables 3 and 4 are given the derived $k_{a}, n$ and $G_{c a l}$ for two selected conditions

\begin{tabular}{ccccccccc}
\hline $\mathrm{t} / \mathrm{s}$ & 0 & 30 & 60 & 90 & 120 & 150 & 180 & 210 \\
\hline $\mathrm{n}$ & 0.98 & 1.06 & 1.18 & 1.30 & 1.40 & 1.47 & 1.49 & 1.48 \\
$\log \left(\mathrm{k}_{\mathrm{a}}\right)$ & -2.14 & -2.41 & -2.76 & -3.09 & -3.43 & -3.74 & -3.98 & -4.16 \\
$\mathrm{G}_{\text {cal }} \times 10^{3} / \mathrm{s}^{-1}$ & 9.5 & 7.5 & 6.2 & 5.8 & 4.6 & 3.7 & 2.7 & 1.9 \\
\hline
\end{tabular}

Table 3: Kinetic parameters $\left(k_{a}\right.$ and $\left.n\right)$ and the corresponding calculated crystallization rate $\left(\mathrm{G}_{\text {cal }}\right)$ for photo-oxidation at $15^{\circ} \mathrm{C}$.

\begin{tabular}{cccccccccccc}
\hline $\mathrm{t} / \mathrm{s}$ & 0 & 120 & 240 & 360 & 480 & 600 & 720 & 840 & 960 & 1080 & 1200 \\
\hline $\mathrm{n}$ & 0.98 & 1.04 & 1.09 & 1.19 & 1.24 & 1.24 & 1.26 & 1.28 & 1.32 & 1.32 & 1.33 \\
$\log \left(\mathrm{k}_{\mathrm{a}}\right)$ & -2.14 & -2.46 & -2.64 & -2.92 & -3.06 & -3.09 & -3.17 & -3.23 & -3.34 & -3.35 & -3.39 \\
$\mathrm{G}_{c a l} \times 10^{3} / \mathrm{s}^{-1}$ & 9.9 & 6.1 & 5.1 & 4.7 & 4.5 & 4.2 & 4.1 & 4.0 & 3.9 & 3.8 & 3.7 \\
\hline
\end{tabular}

Table 4: Kinetic parameters $\left(k_{a}\right.$ and $\left.n\right)$ and the corresponding calculated crystallization rate $\left(\mathrm{G}_{c a l}\right)$ for thermo-oxidation at $75^{\circ} \mathrm{C}$.

\section{Discussion}

The same analytical procedure, described above, has been applied to the experimental data collected from the photoageing at $0,15,35$ and $60^{\circ} \mathrm{C}$ and the thermoageing at $60,75,80$ and $90^{\circ} \mathrm{C}$ of PEO. Figure 4 illustrates the comparison between the isothermal crystallization rate as calculated from Avrami parameters ( $G_{c a l}$, empty symbols) and the same kinetic parameter as directly derived from the experimental relative crystallinity data ( $G_{\text {exp }}$, filled symbols). The good agreement observed between the two series of data reveals that the crystallization kinetics of aged PEO follows the Avrami model. It is, however, worth mentioning that the 
selected procedure, in this work, is not the classical one used in Avrami analysis. Classically, it is performed by varying the selected isothermal crystallization temperature $\left(T_{c}\right) . T_{c}$ is chosen in the range in which polymers can crystallize (i.e. $\mathrm{T}_{\mathrm{g}}<\mathrm{T}_{\mathrm{c}}<\mathrm{T}_{0}$, with $\mathrm{T}_{\mathrm{g}}$ the glass transition and $\mathrm{T}_{0}$ the equilibrium melting temperature). When the melted semi-crystalline polymer is cooled down and maintained at $T_{c}$, it crystallizes with a crystallization rate $(\mathrm{G})$ depending on its degree of supercooling (i.e. $\Delta \mathrm{T}=\mathrm{T}_{0}$-Tc). It is known that $\mathrm{G}$ decreases when $\mathrm{T}_{\mathrm{c}}$ increases. In this work, the isothermal crystallization temperature was kept constant and the same for all experiments whereas the time exposure changes by successive time increments.

Figure 4 should be around here

Figure 5 should be around here

Figure 4 shows that the crystallization rate decreases continuously as a function of exposure time (irradiation or curing time) at each ageing temperature. The melting temperature $\left(\mathrm{T}_{0}\right)$ of PEO is $57^{\circ} \mathrm{C}$ and its glass transition temperature $\left(\mathrm{T}_{\mathrm{g}}\right)$ is $-60^{\circ} \mathrm{C}$. The chosen isothermal temperature $\left(\mathrm{T}_{\mathrm{c}}\right)$ was $55^{\circ} \mathrm{C}$ that corresponds to a very low supercooling. So, as stated in reference [5], it can be assumed that the global kinetics of crystallization is controlled by the nucleation step.

Whatever the ageing temperature for both photo- and thermo-ageing, Avrami exponent, $n$, was found ranging between 0.98 and 1.4. The crystallization seems to proceed with a onedimension nucleation morphology. Beside, the decrease of crystallization rate is accelerated when the ageing temperature increases. As can be seen in Figure 5, comparing the decrease of $\mathrm{G}$ due to the photo-ageing or to the thermo-ageing at the same temperature $\left(60^{\circ} \mathrm{C}\right)$, the light exposure causes also a drastic and fast fall in the crystallization rate. This observed sensitivity of the crystallization rate to irradiation and heating confirms our previous results [14] obtained by a non-isothermal crystallization procedure. During the step of irradiation or heating (at $\mathrm{T}_{\mathrm{a}}$ ) PEO underwent various oxidation reactions. Chain scissions and cross linking are the two more important consequences of these reactions. Cross linking, by the induced drastic limitation of the degree of freedom of the macromolecular chains, could provoke the decrease of the ability of the polymer to crystallize. Also, the chain scissions, by the disordering of the macromolecular segments, prevent the polymer to adopt the right conformation to crystallize. Various evidences, provided by rheology, IR spectroscopy and 
Atomic Force Microscopy (AFM), have been published showing that PEO undergoes a chain scission phenomenon rather than cross linking.

The mechanism given in reference [11] recalls that formates are formed with chain scission whereas the formation of esters does not involve the cleavage of the macromolecular backbone. PhotoDSC, used in this isothermal crystallization mode, gives a reliable and simple way to follow the ageing of semi-crystalline polymers allowing a complete control of light intensity, temperature and atmosphere composition.

\section{Conclusion}

PhotoDSC, combining irradiation, heating and DSC analysis, has been used to follow the photo- and thermo-ageing of a high molecular weight PEO. DSC analysis consisted in the recording of the isothermal crystallization exotherms. It was found that the kinetics of the crystallization of the aged PEO follow the Avrami theory and that the nucleation proceeds by one-dimension morphology $(0.9<n<1.4)$. The isothermal crystallization rate $(\mathrm{G})$ decreases continuously when the exposure time (irradiation or curing time) increases. $G$ decreases also when the ageing temperature increases. When, at the given temperature, PEO is irradiated, the decrease of $G$ is accelerated. The crystallisation rate can be then chosen as a relevant experimental parameter to follow and compare the ageing of semi-crystalline polymers.

\section{References}

1- P. Supaphol, J.E. Spruiell, Polymer 42 (2001) 699-712

2- J.-T. Xu, Y.-Q. Zhao, Q. Wang, Z.-Q. Fan, Polymer 46 (2005) 11978-11985

3- C. Albano, J. Papa, M. Ichazo, J. Gonzalesz, C. Uztariz, Composite structures 62 (2003) 291-302

4- W. Li, X. Kong, E. Zhou, D. Ma, Polymer 46 (2005) 11655-11663

5- P. Supaphol, Thermochimica Acta 370 (2001) 37-48

6- Yeong-Tarng Shieh, Gin-Lung Lui, Kuo Chu Hwang Chia-Chun Chen, Polymer 46(2005)10945-10951.

7- L. Sun, L. Zhu, Q. Ge, R.P. Quirk, C. Xue, S.Z.D. Cheng, B.S. Hsiao, C.A. AvilaOrta, I.Sics, M.E. Cantino. Polymer 45(2004)2931-2939 
8- Harris JM. Poly(ethylene glycol) chemistry: biotechnical an biomedical application. New York: Plenum Press; (1992).

9- Blin J-M, Léonard A, Yuan Z-Y, Gigot L, Vantomme A, Cheetham A.K, Su B.L. . Ange. Chem. Int. Ed (2003), 42, 2872.

10-Rele, Shyam M.; Cui, Wanxing; Wang, Lianchun; Hou, Sijian; Barr-Zarse, Ginger; Tatton, Daniel; Gnanou, Yves; Esko, Jeffrey D.; Chaikof, Elliot L. Journal of the American Chemical Society (2005), 127(29), 10132-10133

11- S. Morlat, J-L Gardette, Polymer, 42 (2004) 6071-6079

12- C. Wilhem, J.-L. Gardette, Polymer (1998);39:5973-80.

13- M. Morel, J. Lacoste and M. Baba M. Polymer, 46(2005) 9274-9282.

14- F. Fraisse, S. Morlat-Therias, J.-L. Gardette, J.-M. Nedelec, and M. Baba, J. Phys. Chem. B (2006), 110, 14678-14684.

15- M. Avrami J. Chem. Phys (1939), 7, 1103

16- M. Avrami J. Chem. Phys (1940), 8, 212

17- M. Avrami J. Chem. Phys (1941), 9, 177 